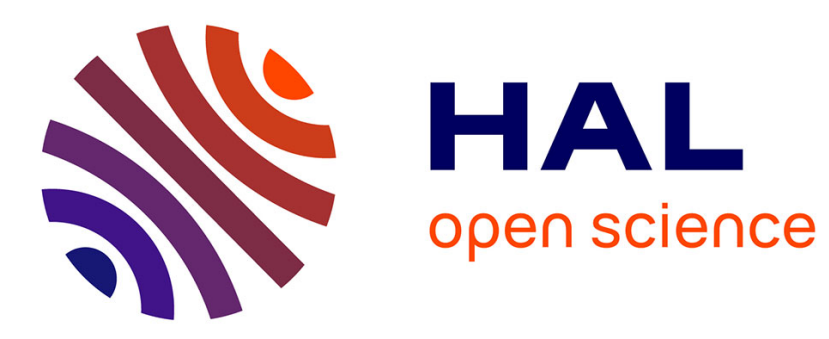

\title{
Plastic behaviour of the steel 20 MnMoNi 55 at transient high velocity loading
}

R. Clos, U. Schreppel, U. Zencker

\section{To cite this version:}

R. Clos, U. Schreppel, U. Zencker. Plastic behaviour of the steel 20 MnMoNi 55 at transient high velocity loading. Journal de Physique IV Proceedings, 1994, 04 (C8), pp.C8-319-C8-323. 10.1051/jp4:1994848 . jpa-00253408

\section{HAL Id: jpa-00253408 https://hal.science/jpa-00253408}

Submitted on 1 Jan 1994

HAL is a multi-disciplinary open access archive for the deposit and dissemination of scientific research documents, whether they are published or not. The documents may come from teaching and research institutions in France or abroad, or from public or private research centers.
L'archive ouverte pluridisciplinaire HAL, est destinée au dépôt et à la diffusion de documents scientifiques de niveau recherche, publiés ou non, émanant des établissements d'enseignement et de recherche français ou étrangers, des laboratoires publics ou privés. 


\title{
Plastic behaviour of the steel 20 MnMoNi 55 at transient high velocity loading
}

\author{
R. Clos, U. Schreppel and U. Zencker
}

Otto-von-Guericke-Universität Magdeburg, Universitätsplatz 2, 39106 Magdeburg, Germany

\begin{abstract}
Résumé - Le comportement dynamique de l'acier 20 MnMoNi 55 a été analysé au moyen de barres de Hopkinson. Toutefois, contrairement au procédé habituel, de courtes impulsions ont été appliquées. Les grandes vitesses de chargement en résultant ont entraîné des vitesses de transformation de l'ordre de quelque $10^{4} \mathrm{~s}^{-1}$ pruvant simulent un comportement du matériau près des points de rupture. Les modèles souvent utilisés de Bodner-Partom et de Perzyna ne sont pas capables de décrire le comportement de cet acier en fonction du temps. C'est pourquoi il a fallu développer, pour ce matériau, une méthode tenant compte du retard au fluage. Dans le modèle, la densité des dislocations de déplacement dépend de l'histoire de chargement.
\end{abstract}

\begin{abstract}
The dynamic deformation behaviour of the steel $20 \mathrm{MnMoNi} 55$ has been investigated using the Split Hopkinson Pressure Bar technique. Contrary to the usual practice short loading pulses were used. In this way highly transient loading conditions were attained with maximum strain rates in the range of $10^{4} \mathrm{~s}^{-1}$, which simulates the situation near rapidly moving crack tips. One result is that the often used viscoplastic material models of BodnerPartom and Perzyna are not suited to describe the transient response behaviour of the investigated steel. A model developed in the present work describes the observed response quite well. The model takes into account delayed yielding. Furthermore it is assumed that the density of mobile dislocations depends on the loading history.
\end{abstract}

\section{INTRODUCTION}

Adequate material equations are necessary for the interpretation of crack propagation and arrest investigations [1,2]. It is typical for rapid crack propagation that material regions are loaded and unloaded within a short time during the passage of the crack tip. They experience a pulse shaped loading connected with maximum strain rates in the order of $10^{5} \mathrm{~s}^{-1}$ [2] or higher [1]. A similar loading regime occurs in dynamic crack initiation experiments at stress pulse loading [3]. Such inherently transient conditions may be simulated by means of the "Split-Hopkinson-Pressure-Bar" technique (SHPB) if contrary to the usual practice short loading pulses are used. In the present work the pressure vessel steel $20 \mathrm{MnMoNi} 55$ is investigated in this way. The maximum strain rates are of the order of $10^{4} \mathrm{~s}^{-1}$. 


\section{EXPERIMENTAL AND THEORETICAL METHODS}

SHPB devices were used with bar diameters of $20 \mathrm{~mm}$ and $15 \mathrm{~mm}$ respectively (Fig. 1). The pulse durations $\tau_{0}$ are $28 \mu \mathrm{s}$ (20 mm device) and $18 \mu \mathrm{s}\left(15 \mathrm{~mm}\right.$ device) respectively ( $\tau_{0}$ denotes the length of the main part of the incident pressure pulse $\sigma_{\mathrm{I}}$, Fig. 2). The thickness $\mathrm{l}_{0}$ and the diameter $\mathrm{d}$ of the specimens were $2 \mathrm{~mm}$ and $18 \mathrm{~mm}$ respectively for the $20 \mathrm{~mm}$ device $(1.5 \mathrm{~mm}$ and $14 \mathrm{~mm}$ for the 15 $\mathrm{mm}$ device). Contrary to the usual measuring technique the incident, reflected and transmitted stresses $\sigma_{I}(t), \sigma_{R}(t)$ and $\sigma_{T}(t)$ were derived from the radial displacements $u_{r}(R, t)$ in the corresponding bars. The radial displacements were measured by means of highly accurate coaxial capacitive gauges (details are given in [4]). The experiments were carried out at different amplitudes of $\sigma_{\mathrm{I}}$ in the temperature range from $-50{ }^{\circ} \mathrm{C}$ up to $100{ }^{\circ} \mathrm{C}$.

Applying the conventional SHPB analysis the mean stress $\sigma$ and mean strain rate $\dot{\varepsilon}$ (both averaged over the specimen thickness) are given by

$$
\begin{gathered}
\sigma(t)=\frac{A_{0}}{2 A_{p}}\left(\sigma_{I}(t)+\sigma_{R}(t)+\sigma_{T}(t)\right) \\
\dot{\varepsilon}(t)=\frac{1}{\rho C_{0} I_{0}}\left(\sigma_{T}(t)-\sigma_{I}(t)+\sigma_{R}(t)\right) .
\end{gathered}
$$

Typical stress and strain rate vs time curves are given in Fig. 3. The corresponding stress vs strain curve shows Fig. 4. It should be noted, that the $\sigma_{I, R, T}(t)$ in the eqs (1) and (2) denotes the values of these quantities at the same time at the boundaries bar - specimen in the corresponding bar. Practically they are measured in some distance from these surfaces of course. For this reason these curves have to be transformed (dispersion correction). While the effect of such an analysis is small if one compares the shape of the measured and the recalculated stress $\sigma_{\mathrm{l}}, \sigma_{\mathrm{R}}$ and $\sigma_{\mathrm{T}}$ vs time curves, there is a pronounced effect on the shape of the stress - strain curve for small strains. The dispersion correction allows the determination of the elastic specimen behaviour from the SHPB data (due to unavoidable uncertainities this does'nt hold for extremely small $\varepsilon$, cf. Fig. 4). Fig. 3 shows the remarkable fact, that there is a time retardation of the maximum values of $\sigma(\mathrm{t})$ and $\dot{\varepsilon}(\mathrm{t})$. The maximum strain rate occurs always some microseconds later than the maximum stress and there are appreciable strain rates in the region of falling stress. This is the reason for the strange stress - strain curves given in Fig. 4. Because the stress as well as the strain are mean quantities (averaged over the specimen thickness according to the conventional SHPB analysis) these curves reflect the global response of the specimen only. (It has to be noted, that the change in sign of $\dot{\varepsilon}$ in Fig. 3 has essentially no physical meaning, the numerical simulations show a loss of contact bars - specimen in this range, this also influences the last short part of $\sigma$ - $\varepsilon$-curves.) They depend on experimental parameters e.g. the thickness of the specimen. The essential question is, what type of constitutive equation produces such a global response? This was investigated by means of an one dimensional numerical analysis of the system bar - specimen - bar using a finite difference code. The numerical determined response of the specimen for different investigated rate dependent material equations was compared with the corresponding results of the (improved) conventional SHPB analysis. Investigated were the Bodner-Partom equation [5]

$$
\dot{\varepsilon}^{p 1}=D e^{-\left(\frac{z}{\sigma}\right)^{2 n}\left(\frac{n+1}{2 n}\right)},
$$

elastic-viscoplastic behaviour with viscoplasticity after a Perzyna law [6]

$$
\dot{\varepsilon}^{p l}=\mu\left(\frac{\sigma}{\sigma_{0}}-1\right)^{p}
$$

as well as a model developed in the present work. The equations for the latter are 


$$
\begin{gathered}
\int^{t_{y}} \frac{\mathrm{d} \tau}{t_{d}[\sigma(\tau)]}=1 \\
\dot{\varepsilon}^{p 1}=b v[\sigma(t)] \int_{t-\Delta}^{t} f[\sigma(\tau)] d \tau \\
\int_{t-\Delta}^{t} v[\sigma(t)] d \tau=1 .
\end{gathered}
$$

Eq (5) determines the onset time $t_{y}$ of plastic deformation. It corresponds to a proposal of Rabotnov et al. [7]. $t_{d}(\sigma)$ denotes the yield delay time at sudden loading by constant stress (cf. Campbell [8]). In the Orowan equation (6) the last term denotes the density $\rho_{\mathrm{m}}$ of mobile dislocations. It is assumed

i) the generation rate $f$ of mobile dislocations depends on the instantaneous stress

ii) all dislocations, which are present at the time $t$, have the same velocity

iii) all dislocations generated at the same time do not contribute to the deformation after a path length 1 , eq (7).

Physically motivated ansatz-functions were used for the functions $t_{d}, v$ and $f$ (details are given in [9]).

\section{RESULTS}

Some results of the analysis are shown in Figs. 5, 6, 7 and 8. For all investigated models the free parameters were fitted. It can be seen, that the stress and strain rate vs time curves for the Perzyna law are not in accordance with the experimental one. Especially the maximum strain rate occurs before the maximum stress, which is contrary to the experiment (cf. Fig. 3 too). The same holds for the BodnerPartom model. The corresponding global stress - strain curves (Fig. 6) show, that these equations are not suited to describe the behaviour of the investigated steel under transient loading. The present model gives on the other hand a good agreement with the observed behaviour (Figs. 7, 8). It has been checked, that all experiments (different pulse amplitude, specimen size and pulse duration) are described quite well with the same set of model parameters. In order to describe the behaviour at different temperatures $\left(-50^{\circ} \mathrm{C}\right.$ up to $\left.100{ }^{\circ} \mathrm{C}\right)$ only few parameters of the model have to be changed.

\section{ACKNOWLEDGEMENT}

This work was supported by the Bundesminister für Forschung und Technologie under Contract 1500851.

\section{REFERENCES}

[1] Kanninen M.F., Hudak S.J., Couque H.R., Dexter R.J. and O'Donoghue P.E., Int. J. Fracture 42 (1990) 239-260.

[2] Freund L.B. and Hutchinson J.W., J. Mech. Phys. Solids 33 (1985) 169-191.

[3] Stroppe H., Clos R. and Schreppel U., Nucl. Engng. Des. 137 (1992) 315-321.

[4] Schreppel U., "Zur definierten Ermittlung von Verformungs- und Bruchkennwerten von Metallen bei Impulsbelastung", Thesis, TH Magdeburg, 1983.

[5] Bodner S.R. and Partom Y., J. Appl. Mech. 42 (1975) 385-389.

[6] Perzyna P., Quart. Appl. Math. 20 (1963) 321-332.

[7] Rabotnov Y.N. and Suvorova J.V., Int. J. Solids Structures 7 (1971) 143-149.

[8] Campbell J.D., Acta met. 1 (1953) 706-710.

[9] Clos R. et al., "Rißverhalten bei Spannungswellenbelastung", BMFT-Report No. 1500 851, 1993. 


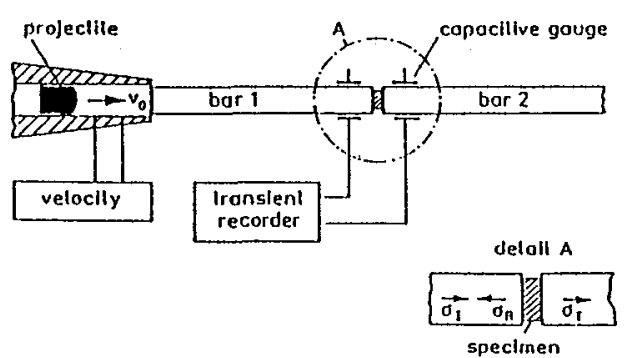

Fig. 1 Experimental setup

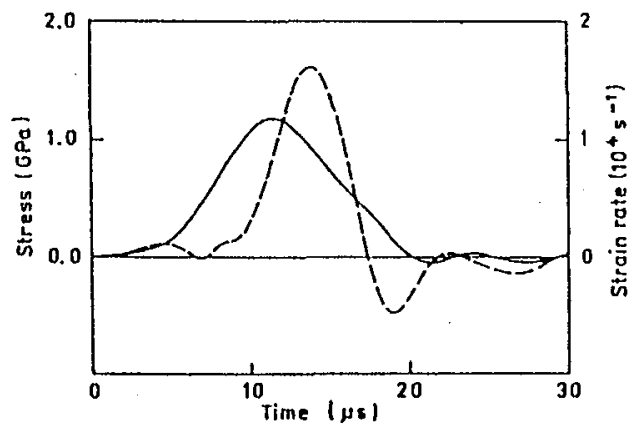

Fig. 3 Typical $\sigma, \dot{\varepsilon}$ vs time curves at short pulse loading, $\tau_{0}=18 \mu \mathrm{s}$, steel $20 \mathrm{MnMoNi} 5 \mathrm{5}, \mathrm{T}=293 \mathrm{~K}$

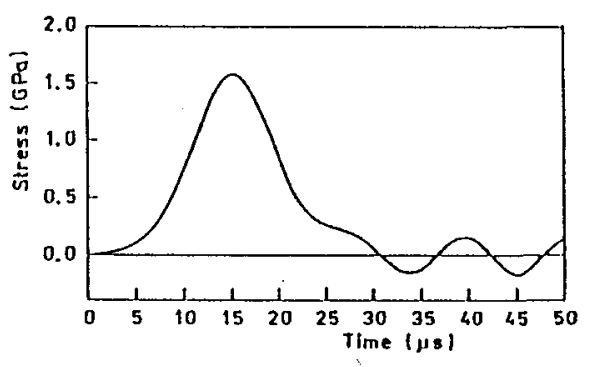

Fig. 2 Typical loading pulse $\sigma_{\mathrm{I}}(\mathrm{t})$, $\tau_{0}=28 \mu \mathrm{s}$

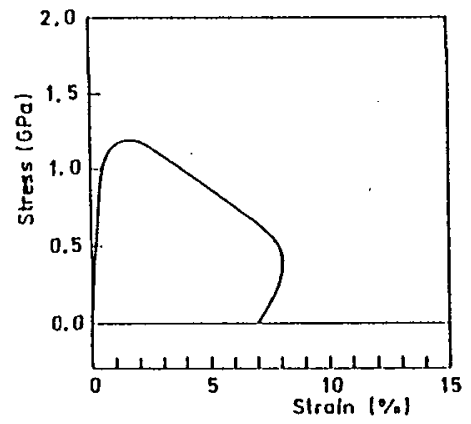

Fig. 4 Stress-strain curve according to Fig. 3 


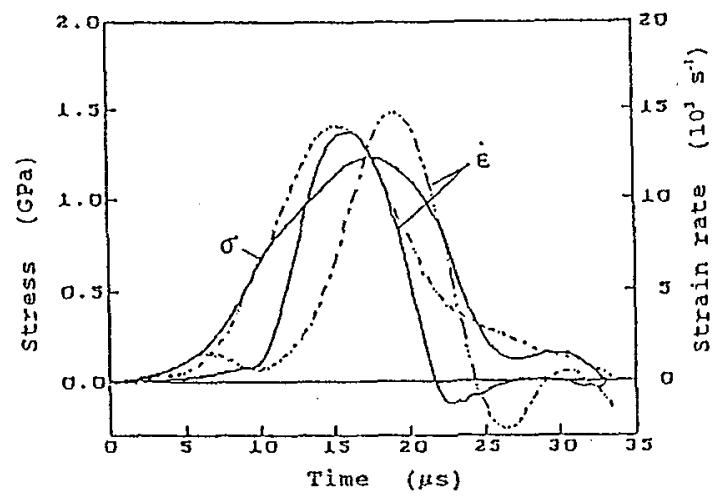

Fig. $5 \sigma, \dot{\varepsilon}$ vs time, numerical analysis using a Perzyna law (exper. curves dotted), $\tau_{0}=28 \mu \mathrm{s}, \mathrm{T}=293 \mathrm{~K}$

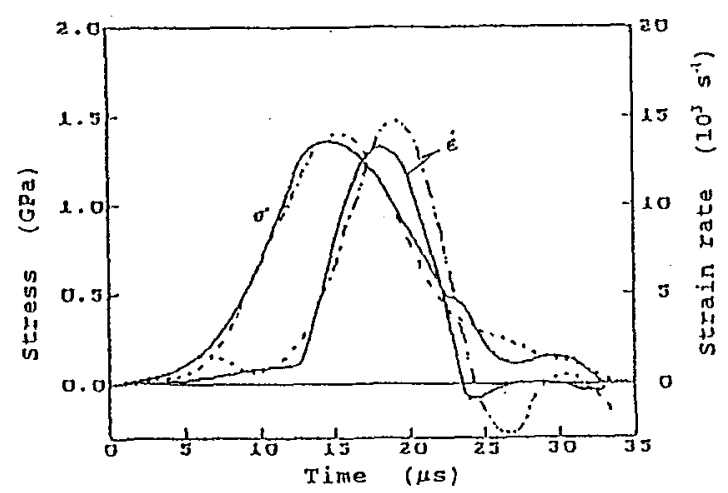

Fig. $7 \sigma, \dot{\varepsilon}$ vs time, present model (exper. curves dotted), parameters as Fig. 5

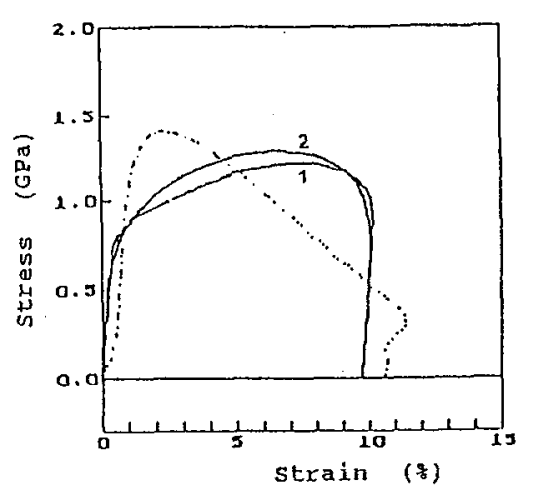

Fig. 6 Stress-strain curves:

1 - Perzyna law

2 - Bodner-Partom eq.

(exper. curve dotted)

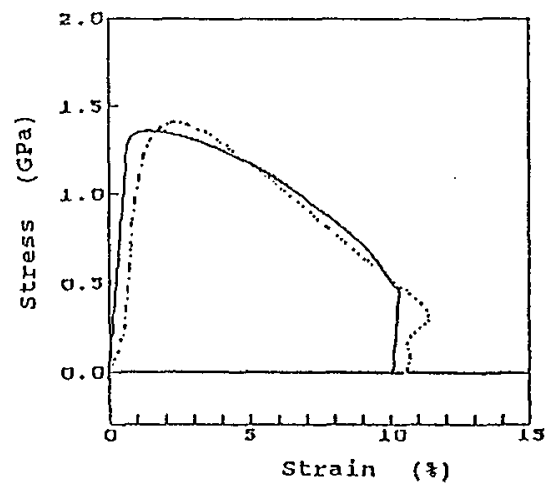

Fig. 8 Stress-strain curves, present model (exper. curve dotted), parameters as Fig. 5 